\title{
Measurement-Based Investigation of Inter- and Intra-Area Effects of Wind Power Plant Integration
}

\author{
Alicia J. Allen, Member, IEEE, Mohit Singh, Member, IEEE, Eduard Muljadi, Fellow, IEEE and \\ Surya Santoso, Senior Member, IEEE
}

\begin{abstract}
This paper has a two pronged objective: the first objective is to analyze the general effects of wind power plant (WPP) integration and the resulting displacement of conventional power plant (CPP) inertia on power system stability and the second is to demonstrate the efficacy of PMU data in power system stability analyses, specifically when knowledge of the network is incomplete. Traditionally modal analysis applies small signal stability analysis based on Eigenvalues and the assumption of complete knowledge of the network and all of its components. The analysis presented here differs because it is a measurement-based investigation and employs simulated measurement data. Even if knowledge of the network were incomplete, this methodology would allow for monitoring and analysis of modes. This allows non-utility entities and study of power system stability. . To generate inter- and intra-area modes, Kundur's well-known two-area four-generator system is modeled in PSCAD/EMTDC. A doubly-fed induction generator based WPP model, based on the Western Electricity Coordination Council (WECC) standard model, is included to analyze the effects of wind power on system modes. The two-area system and WPP are connected in various configurations with respect to WPP placement, CPP inertia and WPP penetration level. Analysis is performed on the data generated by the simulations. For each simulation run, a different configuration is chosen and a large disturbance is applied. The sampling frequency is set to resemble the sampling frequency at which data is available from phasor measurement units (PMUs). The estimate of power spectral density of these signals is made using the Yule-Walker algorithm. The resulting analysis shows that the presence of a WPP does not, of itself, lead to the introduction of new modes. The analysis also shows however that displacement of inertia may lead to introduction of new modes. The effects of location of inertia displacement (i.e. the effects on modes if WPP integration leads to displacement of inertia in its own region or in another region) and of WPP controls such as droop control and synthetic inertia are also examined. In future work, the methods presented here will be applied to real-world phasor data to examine the effects of integration of variable generation and displacement of CPP inertia on inter- and intra-area modes.
\end{abstract}

Index Terms-Electromechanical dynamics, doubly fed induction generators, two-area system, inertia, wind power, PMU

This paper was first submitted for review on $7^{\text {th }}$ May 2013. This work was supported in part by the U.S. Department of Energy.

A. J. Allen was with the National Renewable Energy Laboratory, Golden, CO 80401 USA. She is currently with Sargent \& Lundy LLC. M. Singh was with the National Renewable Energy Laboratory,. He is currently with ComEd. E. Muljadi is with the National Renewable Energy Laboratory. S. Santoso is with the University of Texas at Austin, Austin, TX 78712 USA.

\section{INTRODUCTION}

$\mathrm{W}$ IND penetration levels are increasing across the US. This trend is expected to continue in the following decades [1]. In certain regions of the US, peak penetration levels can approach $30 \%$ [2]. At these penetration levels it is expected that wind power plants will, in many cases, displace conventional generation. This displacement may be permanent due to conventional plant retirements based on emissions- or age-related concerns and due to utilities preferring to install wind power plants instead of new conventional generation [3]. This displacement may also be a result of operational decisions, as high wind conditions may lead to increased wind power output and consequently a reduction of online conventional generation to meet demand [4]. This displacement of conventional synchronous generation by asynchronous WPPs will have significant stability impacts. In this paper, we focus on inter- and intra-area oscillation modes in particular. The effect of high wind penetration levels on oscillation modes in real power systems is largely unknown. Numerous simulation-based studies have been conducted, with inconclusive results suggesting that damping of modes may be improved or worsened by wind [5-8]. The consensus appears to be that WPPs do not participate directly in oscillation modes; however, their presence leads to displacement of CPP inertia and other topology changes that have the potential to influence the oscillation modes [8]. In our present work, we model a familiar two-area test system [9] with an additional WPP. The key finding is that not only does the displacement of inertia affect modes but the area in which the inertia is displaced affects the modes as well. The area in which the inertia is displaced may affect both the frequency and damping of an oscillation mode. This is relevant since WPPs may displace conventional plant inertia in regions other than the one they are situated in, due to wind resources being far from load centers as well as due to economic or other factors. The two-area system model is a time-domain model developed using the PSCAD/EMTDC platform [10]. This platform was chosen for its short simulation time-step, giving insight into any dynamics that may appear. This platform has been used before for two-area stability analyses [11]. The output from the simulations can be filtered and downsampled to simulate PMU data. The WPP model is based on the WECC Wind 
Generator Modeling Group's standard model for Type 3 (Doubly Fed Induction Generator) wind power plants [12]. The standard model is ported to PSCAD/EMTDC based on the work reported in [13]. Additional controls for synthetic inertia and voltage droop have been added to the standard model. A detailed explanation of model development is provided in Section II.

In the future, long-term phasor measurement unit (PMU) data from real power systems can provide information about changes in oscillation modes due to wind-related or other topology changes. Currently PMUs are envisioned as a tool for enhancing stable operations of the grid but as PMU penetration improves a vast amount of data will be archived and available that could provide information about the effect of network changes on stability. This information could aid planners in evaluating the impacts of proposed generator or line additions. In an environment where system data may be frequently changing or may not be readily available, traditional eigenvalue analysis to find damping of modes can be challenging. Instead, signal processing methods can be applied to PMU data to gather information about modes. In the work presented here, a method based on the Yule-Walker algorithm [14] is applied to analyze the simulated PMU data generated by the model. This method can be applied to real PMU data in the future. A description of the method is provided in Section III. Numerous scenarios are simulated using the model. Different WPP output levels, different locations of the WPP, different areas of inertia reduction among other factors are investigated with respect to changes seen in oscillation modes. These scenarios are discussed in detail in Section IV. The results of the analysis support the consensus in the literature that the WPP does not participate in the oscillation modes but affects them indirectly through displacement of inertia. The results also indicate that WPP frequency response controls appear to have little impact on the modes. Detailed results and discussion are provided in Section V.

\section{Model Development}

The model used for these simulations was developed in two stages. In the first stage, a model of the two-area system was developed in PSCAD/EMTDC. In the next stage, a model of the WECC standard wind power plant was developed and integrated into the two-area system model. The original WECC model was intended for phasor-based modeling software such as PSLF or PSS/E [15]. In our work, we use a time-domain PSCAD/EMTDC equivalent of the WECC model (discussed in detail in [13]).

\section{A. Two-area system model}

A one-line diagram of the two area system is shown in Fig. 1. The base system is symmetrical in terms of generation and line impedance. The model parameters are taken from [9]. In steady state conditions with no wind there is a $400 \mathrm{MW}$ transfer from area 1 to area 2 across the weak transmission tie between the areas. It should be noted that in our model power system stabilizers (PSS) and Automatic Generation Control
(AGC) are not included. However, each generator's excitation system and governor has been modeled. PSCAD/EMTDC parameters for modeling generators and controls not provided in [9] are left at default values where reasonable. Each generator is rated at 900 MVA. For this analysis, high frequency transients are not studied and a coupled-pi transmission line representation is used for modeling all transmission lines in the system.

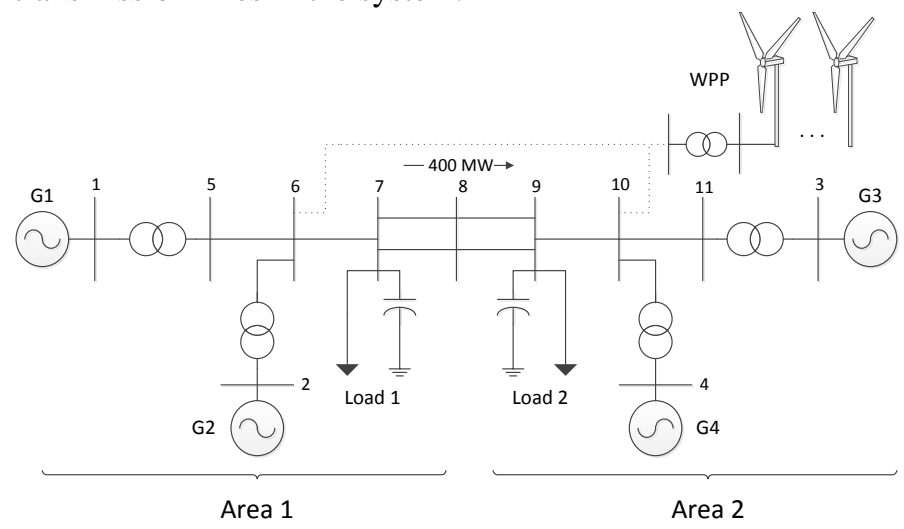

Fig. 1. Two-area system from Kundur [9] with additional WPP.

\section{B. Wind Power Plant Model}

The WPP model is a PSCAD/EMTDC equivalent of the DFIG WPP model developed by the WECC Wind Generator Modeling Group. A schematic of the WECC DFIG WPP model is provided in Fig. 2 to illustrate the model framework.

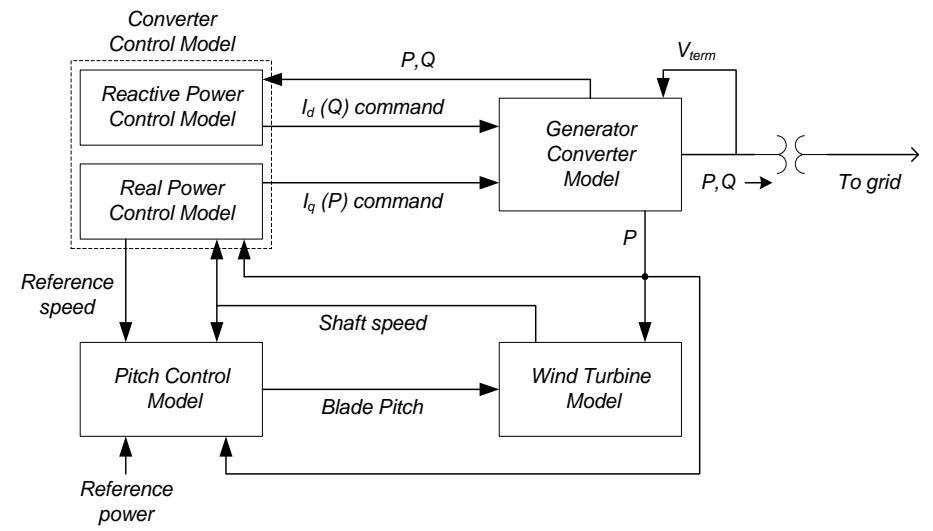

Fig. 2. Schematic of WECC DFIG WPP model.

The WPP is sized such that wind penetration level in the two-area system is $10 \%$ when the WPP is supplying its rated power of $400 \mathrm{MW}$. The WPP collector system model is represented by an aggregated single-line equivalent. Details on how this aggregation is performed are provided in [16]. The collector system data for the aggregation process is from a real WPP and is presented in [16]. The WECC DFIG WPP model is a well-documented work and the parameters for the model are available in [15].

\section{Additional Wind Power Plant Controls}

Additional wind power plant controls may be provided by the turbine manufacturer for the purpose of frequency support. These controls are evaluated in our analysis because they change the active power output of the plant and may react to 
power swings. These controls include governor droop control and synthetic inertia. Detailed explanations of droop control and synthetic inertia are provided in [17-20]. The effects of these controls on oscillation modes are unknown. In this paper, these controls are implemented as non-standard additions to the WECC WPP model and their effect on modal behavior is examined. Each controller is examined independently and their combined action is examined as well. The droop control is based on a droop curve with a $50 \mathrm{mHz}$ deadband and 5\% droop setting [21]. The control changes the reference power signal originating within the WECC model as shown in Fig. 3. The controller shown here is a modified version of the controller described in [22]. The ability to use either droop or synthetic inertia or both is provided using two On/Off switches.

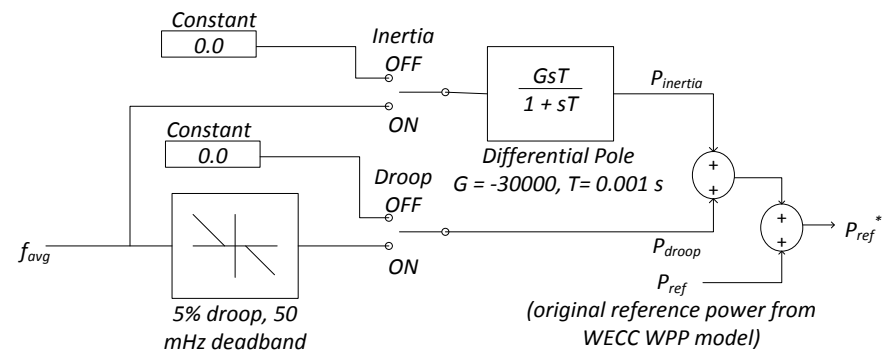

Fig. 3. Control block diagram for droop control and synthetic inertia.

\section{Simulated Phasor Data Processing}

Synchronized phasor measurements are high precision timesynchronized measurements and have the ability to provide information on the interconnected power system's electromechanical modal behavior. Electromechanical modal information consists of modal frequencies and damping and mode shape. This information is extracted from synchronized phasor measurements using signal processing methods and are described in this section. Pseudo-phasor measurements are created using the simulated two-area system described in Section II. These pseudo-phasor measurements are similar to real power system measurements taken by PMUs because they are also high-precision and time-synchronized. The advantage of using the simulated system instead of real data is that changes to the system (such as changes to generator inertia or wind plant location) can be made and their effect on modal behavior can then be studied. The number of observations per second is also higher in the simulation phasor measurements. The pseudo-measurements are filtered and downsampled to the typical 30 observations per second for PMU measurements [23].

In this paper, three different signal processing methods are used to extract modal information from the simulation phasor measurements. The first method, the matrix-pencil (MP) method [24,25], is a linear, time-domain method that fits a linear model to the evenly spaced pseudo-measurements. The MP method is used to estimate the modal frequencies and damping that are present in the system. For the second method, the power spectral density (PSD) is estimated based on auto-regressive (AR) model fitting using the Yule-Walker
(YW) method [25]. For the AR YW method, the modes of the system arise in response to a step change, i.e., a sudden change in load. The AR YW method can also be used when the analyzed signal contains white noise as described in [14]. The PSD provides a visual representation of the strengths of the modal frequencies present in the pseudo-measurements. Significant peaks in the PSD indicate dominant frequencies present in the measurements. The third method applies spectral analysis to the pseudo-measurements to estimate the mode shape. The cross-spectral density (CSD) is estimated using Welch's periodogram averaging [26]. The angle of the CSD provides information on the mode phasing. It is used to show which generators are swinging together or against each other. Linear trends are removed from the pseudomeasurements before the signal-processing methods are applied [27]. Results of these methods applied to pseudomeasurements for a number of different cases are provided in Section V.

\section{Simulation Cases}

Simulations were performed in a number of different configurations with respect to wind power output level, wind plant location and inertia displacement location. The cases are listed in Table I. The base case is the unmodified two-area system with no WPP. In cases 1 to 10 a WPP is present, connected either in Area 1 (bus 6) or Area 2 (bus 10). The WPP's presence leads to a reduction in inertia either in Area 1 (inertia reduced to a third of the original value for Generator G2) or in Area 2 (inertia reduced to a third of the original value for Generator G4). Each of the synchronous units G1 through G4 is assumed to be a perfectly coherent representation of multiple synchronous generators. The presence of wind leads to displacement of CPPs, hence a reduction in the number of machines making up a coherent unit. This is represented in our simulation by a reduction in the inertia of that coherent unit. The decision to reduce inertia on coherent units to a third of their value represents removal of turbogenerators (typical inertia 3-9s) from a coherent unit while hydro units (typical inertia 2s) remain [28].

Three wind power output levels were considered: $0 \mathrm{pu}, 0.5$ $\mathrm{pu}$ and $1 \mathrm{pu}$. Increased wind may lead to displacement of CPPs, however, the wind output may be near 0 pu for some time periods. Cases 1 and 2 are included to represent this condition and are different from the base case. In these cases the location of the WPP is immaterial since the output is $0 \mathrm{pu}$ and the reactive power is controlled to be zero at the WPP's point of common coupling (PCC). In cases 3, 4, 5 and 9 the WPP output is at 0.5 pu. In cases $6,7,8$ and 10 the WPP output is at $1 \mathrm{pu}$. Comparison of these two groups of cases provides insight into how WPP output affects modes.

The WPP is located in Area 1 in cases 4, 5, 7 and 8, and in Area 2 in cases 3, 6, 9 and 10. Comparison of these groups of cases can provide insight into how wind plant location affects modes. If the two-area system were perfectly symmetrical, the location of the WPP (bus 6 or bus 10) would not be expected to have an effect. However, the loads are non-symmetrical in the two-area system with Area 2 more heavily loaded than 
Area 1.Thus changing the location of the WPP is effectively changing the electrical distance of the WPP from the load center and changes in modal behavior may occur.

The inertia reduction occurs in Area 1 in cases 2, 5, 8, 9, and 10, and occurs in Area 2 in cases 1, 3, 4, 6, and 7. In certain cases the area of inertia reduction coincides with WPP location while in other cases it does not. The load asymmetry ensures that each of these cases is unique. The reduction of inertia and the location of this inertia reduction were found to have a significant effect on the modal behavior.

TABLE I

LIST OF CASES BASED ON WIND POWER OUTPUT, WIND LOCATION AND INERTIA REDUCTION LOCATION

\begin{tabular}{|c|c|c|c|}
\hline Case No. & $\begin{array}{c}\text { Wind } \\
\text { Power } \\
(\mathrm{pu})\end{array}$ & $\begin{array}{c}\text { Wind } \\
\text { Location } \\
\text { (Area) }\end{array}$ & $\begin{array}{c}\text { Inertia } \\
\text { Reduction } \\
\text { (Area) }\end{array}$ \\
\hline Base Case & 0 & - & - \\
\hline 1 & 0 & - & 2 \\
\hline 2 & 0 & - & 1 \\
\hline 3 & 0.5 & 2 & 2 \\
\hline 4 & 0.5 & 1 & 2 \\
\hline 5 & 0.5 & 1 & 1 \\
\hline 6 & 1 & 2 & 2 \\
\hline 7 & 1 & 1 & 2 \\
\hline 8 & 1 & 1 & 1 \\
\hline 9 & 0.5 & 2 & 1 \\
\hline 10 & 1 & 2 & 1 \\
\hline
\end{tabular}

\section{A. Additional Wind Power Plant Controls}

In the simulation cases described so far the droop and synthetic inertia controls were disabled. Additional cases were simulated with the droop and synthetic inertia wind power plant controls enabled. These controls were tested only for the cases $6,7,8$ and 10 where wind output was $1 \mathrm{pu}$. For the sake of brevity only case 10 results are shown here. Results from case 10 with droop and inertia controls disabled were taken as the base case. Three additional cases, were simulated; the first (case 10a) with inertia alone enabled, the next (case 10b) with droop alone enabled and the last (case 10c) with both enabled.

\section{RESULTS}

Results from the case studies are presented here. The simulated two-area system is excited by a large disturbance a breaker connecting an impedance load in parallel to load 2 located at Bus 9 in Fig. 1 is suddenly switched on. The additional load is $1 \%$ of load 2 in terms of real and reactive power. The signal processing methods described in Section III are applied to the resulting electromechanical oscillations to estimate the modal frequency, damping and the mode shape of the system. The estimated modes for each case are compared to determine if the WPP output levels, the location of the wind power plant, or the location of reduction in inertia influence the system modes.

\section{A. Power Spectral Density Analysis}

For the case studies, the frequency at each generator bus, the voltage phase angle with respect to the calculated center of angle [9], the voltage phase angle at each generator bus, and the power output at each generator were used to estimate the modes of the system after the power system disturbance was applied. The results of analysis on the power output at each generator are presented in Figs. 4 to 7. The power output signal was selected to analyze modes because the mode estimates were clearest for this signal in comparison to the voltage phase angle and frequency signals. In Fig. 4, the significant peaks in the PSD indicate modal frequencies present in the power output at Generator 1 located at Bus 1 for all cases. The PSD in Fig. 4 (top) indicates the presence of $0.73 \mathrm{~Hz}$ (for the base case) and $0.76 \mathrm{~Hz}$ for the cases where the WPP output is zero (cases 1 and 2). The approximate 0.73 $\mathrm{Hz}$ and $0.76 \mathrm{~Hz}$ frequencies fall in the inter-area oscillation range $(0.1$ to $0.8 \mathrm{~Hz})$ [29] indicating that this frequency is associated with one group of generators oscillating against another group of generators in the system. The inertia of the system is symmetrical for the base case and unsymmetrical in Cases 1 and 2. The first observation is that the reduction in inertia in either area does influence modes of the system specifically the inter-area mode present in the two-area system. The same frequency $(0.76 \mathrm{~Hz})$ is present where the wind power output is 0.5 pu as shown in Fig. 4 (middle) and 1.0 pu in Fig. 4 (bottom). The lack of significant additional peaks when wind power is present indicates that the WPP output levels investigated do not have a direct impact on the modes of the system.

In Fig. 5, the same cases are studied but the power output of Generator G2 located at Bus 2 is analyzed. The PSD results are shown and in addition to the $0.76 \mathrm{~Hz}$ mode, modal frequencies at $1.75 \mathrm{~Hz}$ and $1.87 \mathrm{~Hz}$ are visible as significant peaks. Frequencies in this range are associated with intra-area oscillations $(0.7$ to $2.0 \mathrm{~Hz})$ - when a single generator oscillates against another generator or group of generators [29]. However, the intra-area oscillations are not impacted by wind power penetration but by the location of decrease in inertia in the system. For the base case, the inertia is symmetrical and only the inter-area frequency $(0.73 \mathrm{~Hz})$ is seen. When the inertia in Area 1 is reduced (cases 2, 5, 8, 9 and 10), in addition to the $0.76 \mathrm{~Hz}$ frequency a $1.75 \mathrm{~Hz}$ frequency is seen as a significant peak in the PSD. When the inertia in Area 2 is reduced (cases 1, 3, 4, 6 and 7), in addition to the $0.76 \mathrm{~Hz}$ frequency a $1.87 \mathrm{~Hz}$ frequency is seen as a significant peak in the PSD. The PSD for the base case includes additional modes when the power output from Generators G3 and G4 (located in Area 2) is used as shown in Figs. 6 and 7. The same shift in the base case inter-area mode $(0.73 \mathrm{~Hz})$ to $0.76 \mathrm{~Hz}$ when the inertia is reduced in either Area 1 or Area 2 is seen here. In addition, for Generator G3, a significant peak at $1.17 \mathrm{~Hz}$ for the base case is seen in the PSD in Fig. 6. When the inertia in Area 1 is reduced, the $1.17 \mathrm{~Hz}$ frequency shifts to a $1.2 \mathrm{~Hz}$ frequency. When the inertia in Area 2 is reduced, the $1.17 \mathrm{~Hz}$ frequency shifts to $1.78 \mathrm{~Hz}$. For Generator G4, a significant peak at $1.29 \mathrm{~Hz}$ for the base case is seen in the PSD in Fig. 7. However, when the inertia is reduced in Area 1 the modal 
frequency does not change and is still at $1.29 \mathrm{~Hz}$. When the inertia in Area 2 is reduced, the $1.29 \mathrm{~Hz}$ shifts to $1.75 \mathrm{~Hz}$.

Comparing the case study results to the base cases for Generator G3 and G4, the same observation is made as in Area 1 generators - the reduction in inertia in either area does influence modes of the system. However, in this case the reduction in inertia changes both the inter-area mode $(0.73$ $\mathrm{Hz})$ and the intra-area modes $(1.17 \mathrm{~Hz}, 1.29 \mathrm{~Hz}$, and $1.75 \mathrm{~Hz})$.
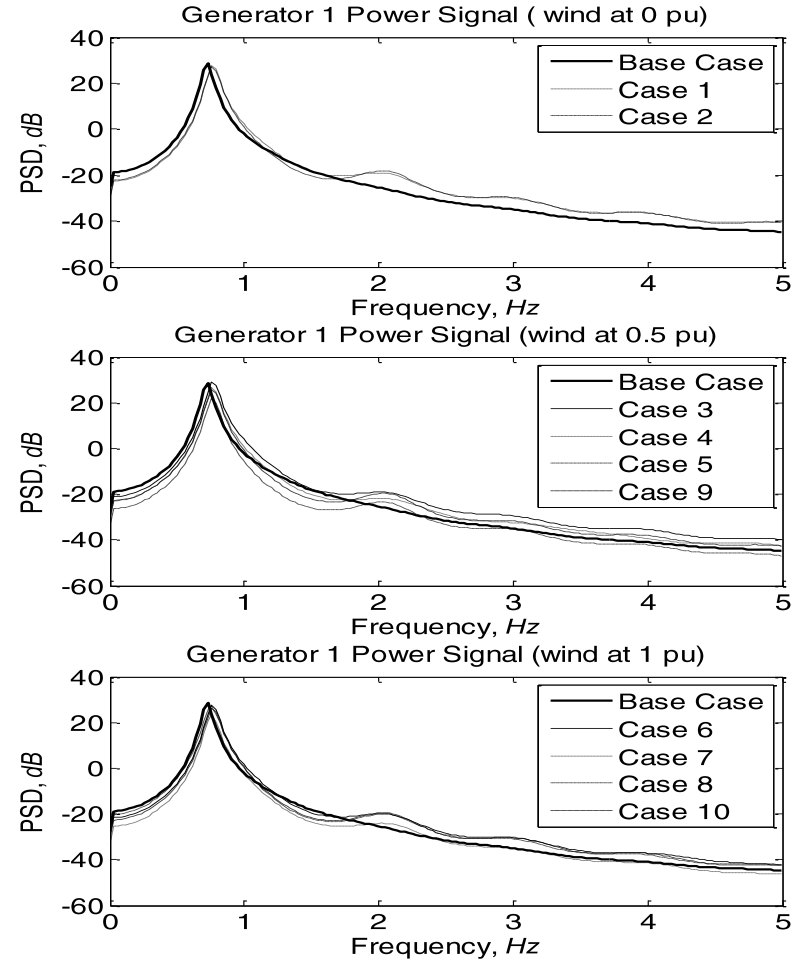

Fig. 4. Yule-Walker PSD estimates for Generator G1 power signal.
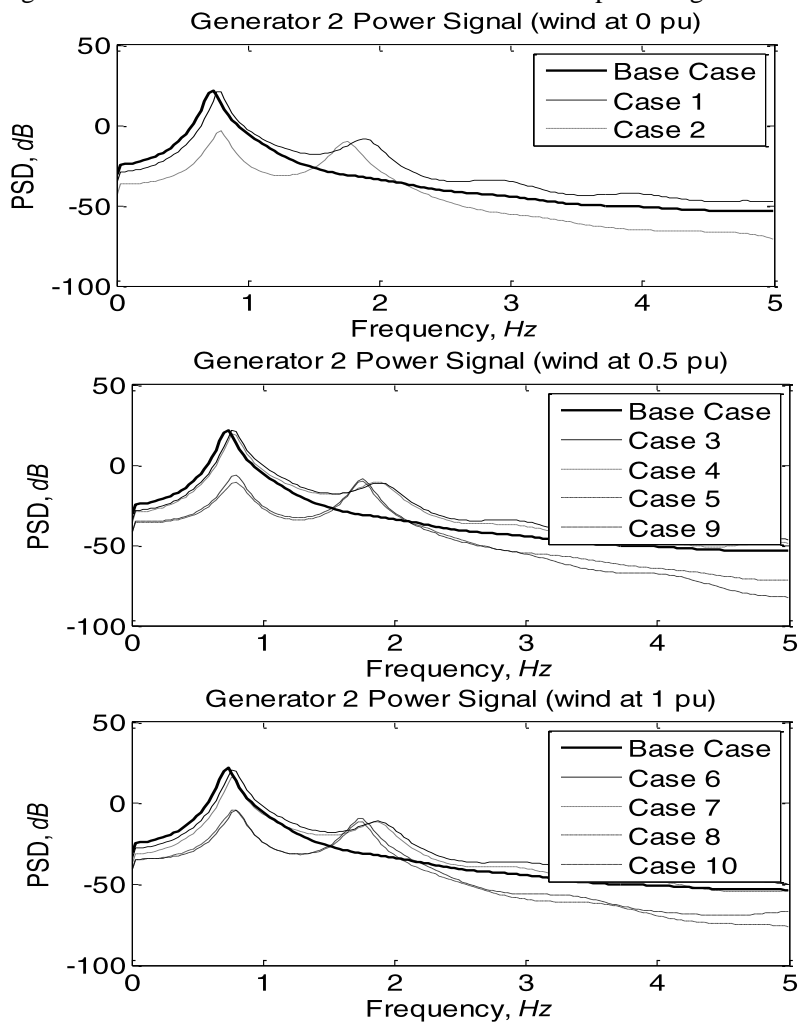

Fig. 5. Yule-Walker PSD estimates for Generator G2 power signal.
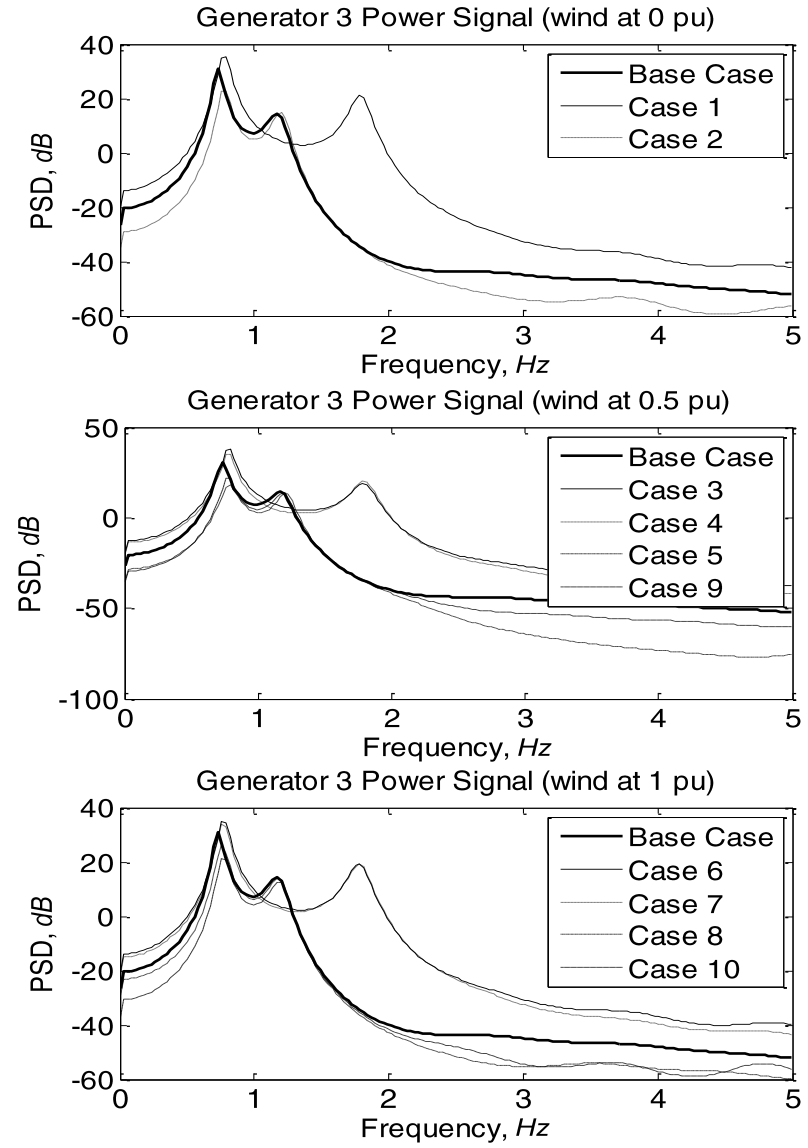

Fig. 6. Yule-Walker PSD estimates for Generator G3 power signal.
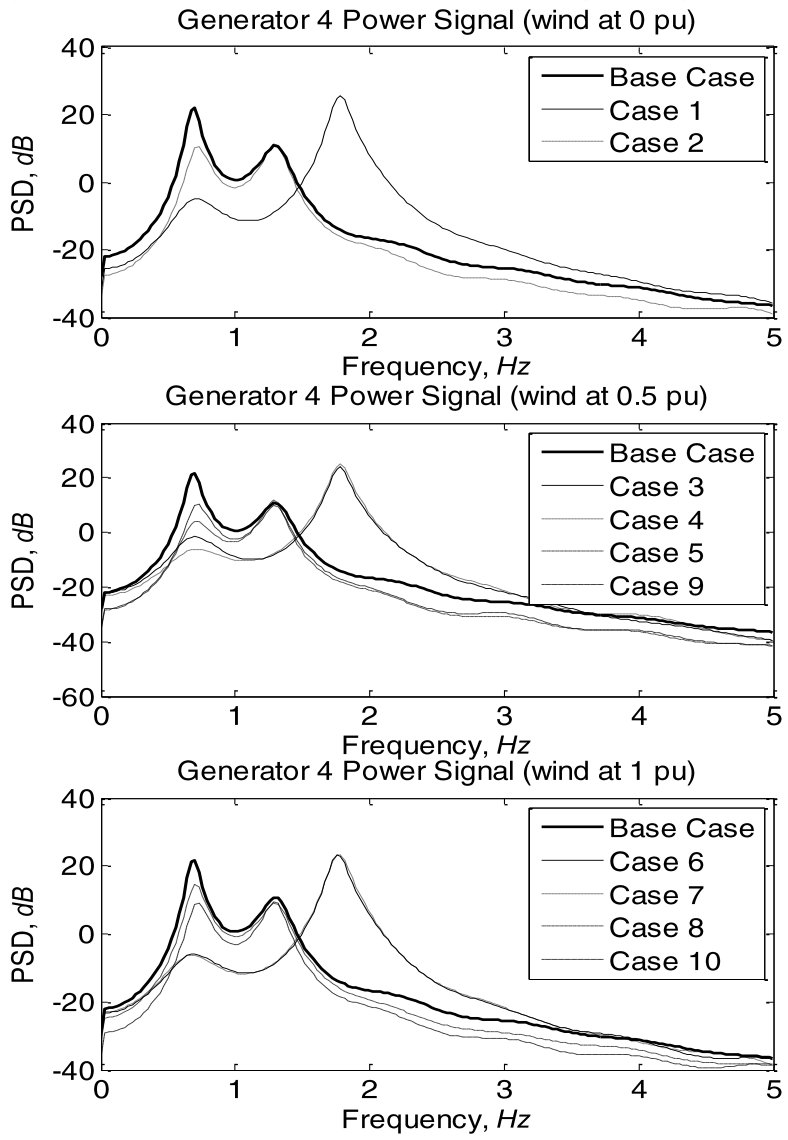

Fig. 7. Yule-Walker PSD estimates for Generator G4 power signal. 


\section{B. Cross-Spectral Density Analysis}

In this section the CSD is used to estimate the mode shape. The mode shape is used to determine which generators are involved in each mode and which generators are oscillating against one another or are oscillating together. The CSD between the following pairs of generators are examined: Generator G2 and G4, Generators G1 and G2, and Generators G3 and G4. The results for the base case and for case 10 are shown in Figs. 8 and 9. In Fig. 8 (top), there are significant peaks at $0.73 \mathrm{~Hz}$ (represented by $\square$ ) and $1.22 \mathrm{~Hz}$ (represented by $\nabla$ ). The corresponding frequency in the CSD is used to determine if two generators are oscillating together or against one another for the base case. In Fig. 8 (second from top), the CSD between Generators G2 and G4 shows that the $0.73 \mathrm{~Hz}$ mode is $180^{\circ}$ out of phase; thus Generator G2 from Area 1 is oscillating against Generator G4 from Area 2. The relationship between Generator G2 and G4 for the $1.22 \mathrm{~Hz}$ mode is not as clear - for this mode there is a $111^{\circ}$ phase difference. In Fig. 8 (second from bottom), for the inter-area $0.73 \mathrm{~Hz}$ mode, Generators G1 and G2 oscillate together. For the intra-area $1.22 \mathrm{~Hz}$ mode, there is a $150^{\circ}$ phase difference. In Fig. 8 (bottom), for the inter-area $0.73 \mathrm{~Hz}$ mode, Generators G3 and G4 oscillate together. For the intra-area $1.22 \mathrm{~Hz}$ mode, there is a $180^{\circ}$ phase difference, indicating that the two generators oscillate against one another at this frequency. In Fig. 9 (top), significant peaks at $0.73 \mathrm{~Hz}(\square), 1.22 \mathrm{~Hz}(\nabla)$ and $1.75 \mathrm{~Hz}(\diamond)$ are visible for the case 10 example. The $0.73 \mathrm{~Hz}$ mode behaves similarly to the previous base case example. Generators in Area 1 oscillate against the generators in Area 2. When two generators are in the same area, the generators oscillate together for this frequency. Fig. 9 (second from top) shows that for the $1.75 \mathrm{~Hz}$ mode, the phase angle shift between generators $\mathrm{G} 2$ and G4 is $-160^{\circ}$. Fig. 9 (second from bottom) shows that generators $\mathrm{G} 1$ and $\mathrm{G} 2$ oscillate against one another for the approximately $1.2 \mathrm{~Hz}$ mode. For the $1.75 \mathrm{~Hz}$ mode, the generators also oscillate against one another. The CSD between generators G3 and G4 in Fig. 9 (bottom) shows that for the $1.22 \mathrm{~Hz}$ mode G3 and G4 are oscillating against one another and for the $1.75 \mathrm{~Hz}$ mode they are oscillating together. These CSD angle estimates enable the association of modes with areas; for example, the $1.75 \mathrm{~Hz}$ mode is associated with area 1. Changes in inertia in an area will affect these local modes.

\section{Matrix-Pencil Analysis Technique}

The influence of wind power, location of the WPP, and reduction in inertia on modal damping is examined in this section. The Matrix-Pencil method is used to estimate the modal frequency and damping in each generator power output for all 11 case studies. Table II shows the frequency and damping estimates for generators G1 and G2 located in Area 1. The inter-area $0.73 \mathrm{~Hz}$ mode is seen in the power output for the generators in Area 1 as shown in Table II. As seen earlier in this section, the $0.73 \mathrm{~Hz}$ mode shifts to approximately 0.77 $\mathrm{Hz}$ when the inertia is reduced in either Area 1 or Area 2. The damping estimates for cases 1 to 10 indicate that the $0.77 \mathrm{~Hz}$ mode is better damped for cases when the inertia is reduced in Area 1 or in Area 2 and is not dependent on wind power penetration or on wind power plant location.
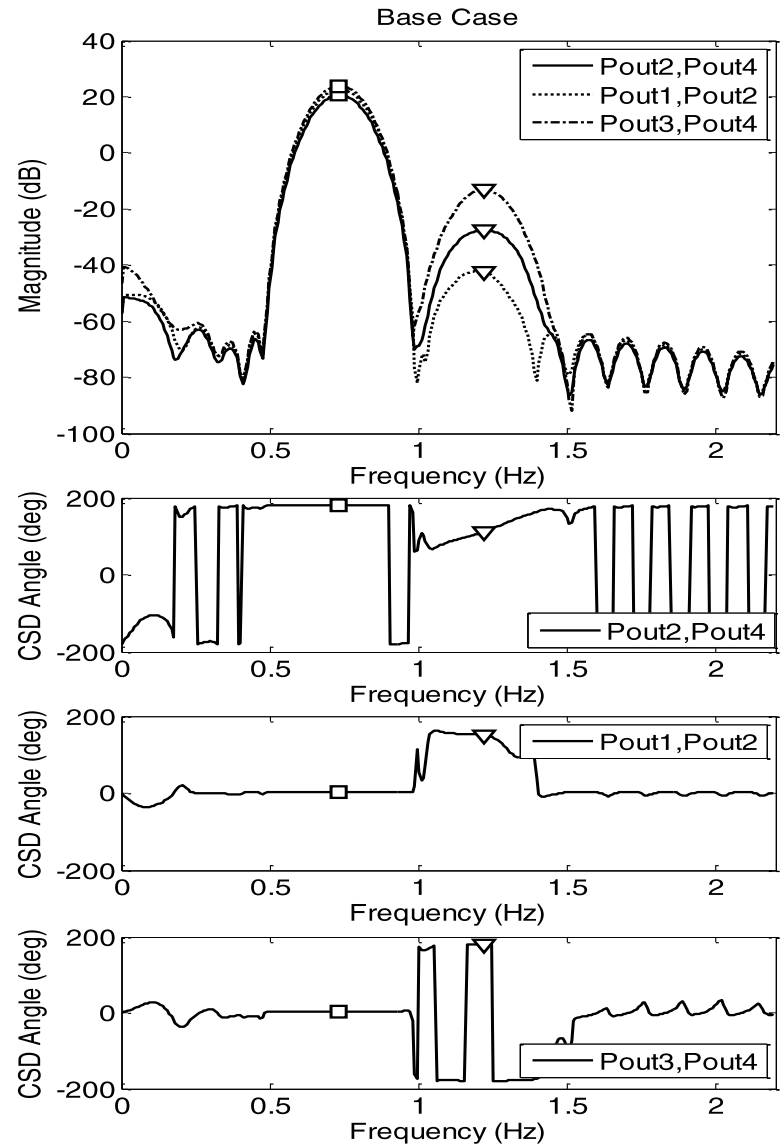

Fig. 8. PSD and CSD angle estimates. $\square$ indicates the $0.73 \mathrm{~Hz}$ mode and $\nabla$ indicates the $1.22 \mathrm{~Hz}$ mode.
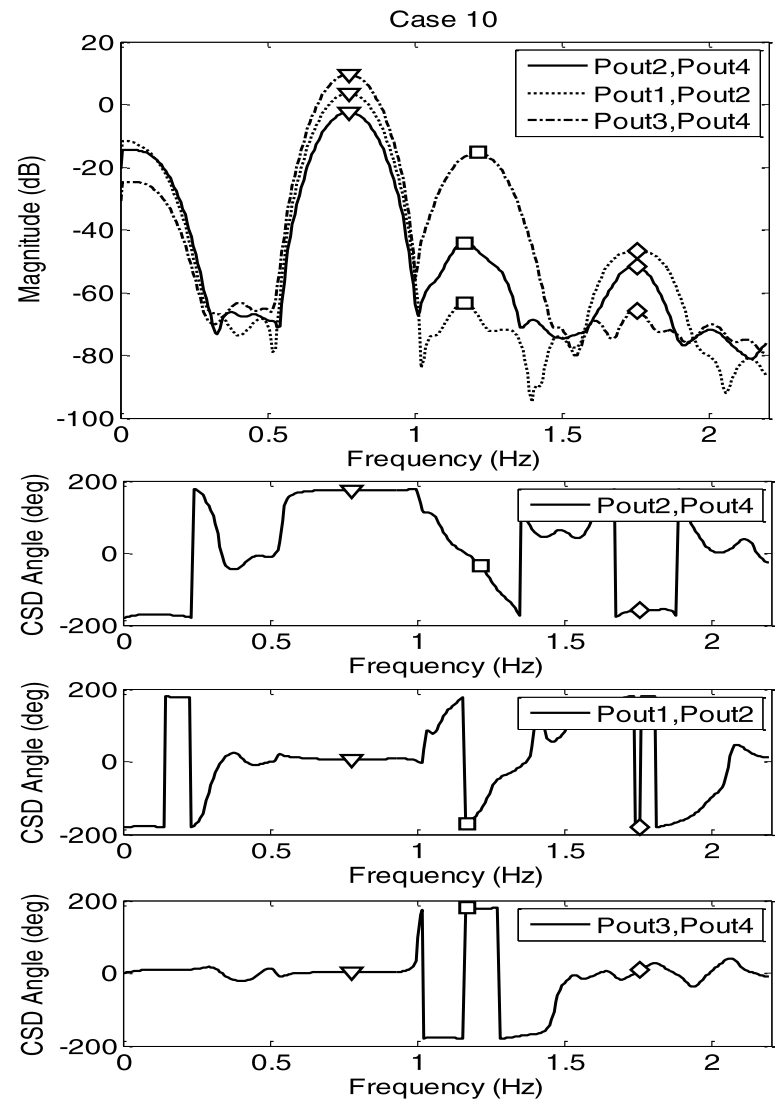

Fig. 9. PSD and CSD angle estimates. $\square$ indicates the $0.73 \mathrm{~Hz}$ mode, $\nabla$ indicates the $1.22 \mathrm{~Hz}$ mode and $\diamond$ indicates the $1.75 \mathrm{~Hz}$ mode. 
Table III shows the estimated modal frequencies and damping for generator G3 located in Area 2. A $1.22 \mathrm{~Hz}$ mode is seen in the power output of generator G3 in addition to the inter-area $0.73 \mathrm{~Hz}$ mode. As seen earlier in this section, when the inertia in Area 1 in reduced, the $1.22 \mathrm{~Hz}$ frequency shifts to $1.78 \mathrm{~Hz}$. The damping for the $0.73 \mathrm{~Hz}$ mode is improved when the inertia is reduced in Area 1 or in Area 2 and is not dependent on wind power penetration or on wind power plant location. The damping for the $1.22 \mathrm{~Hz}$ mode is not altered by wind power penetration, location of the wind power plant, or by the reduction of inertia. Similar results are seen for the estimated modal frequencies and damping for generator G4 located in Area 2 are given in Table IV.

\section{Modes with Additional Wind Power Plant Controls}

The additional controls added to the wind power plant to improve frequency response perform as expected, as shown by the system average frequency response plot in Fig. 10. The case with both droop and inertia enabled performs best in terms of frequency response. Tables VI and VII list the frequency and damping of each mode observed for each of the cases. In terms of modal behavior there is no significant difference between any of the cases shown here. It can thus be inferred that these controls do not have significant impact on modal behavior. More aggressive droop curves and control modifications will be studied in future work to determine if these controls may affect modal behavior.

TABLE II

AREA 1 FREQUENCY AND DAMPING ESTIMATES FOR 0.73 Hz MOdE

\begin{tabular}{|c|c|c|c|c|}
\cline { 2 - 5 } \multicolumn{1}{c|}{} & \multicolumn{2}{c|}{ Generator G1 } & \multicolumn{2}{c|}{ Generator G2 } \\
\hline Case No. & Freq & Damp & Freq & Damp \\
\hline Base & 0.73 & 0.07 & 0.73 & 0.06 \\
\hline 1 & 0.78 & 0.29 & 0.78 & 0.28 \\
\hline 2 & 0.77 & 0.41 & 0.77 & 0.61 \\
\hline 3 & 0.78 & 0.39 & 0.78 & 0.36 \\
\hline 4 & 0.78 & 0.38 & 0.78 & 0.37 \\
\hline 5 & 0.77 & 0.48 & 0.77 & 0.63 \\
\hline 6 & 0.77 & 0.47 & 0.78 & 0.47 \\
\hline 7 & 0.77 & 0.53 & 0.77 & 0.58 \\
\hline 8 & 0.76 & 0.54 & 0.76 & 0.64 \\
\hline 9 & 0.77 & 0.46 & 0.78 & 0.57 \\
\hline 10 & 0.77 & 0.61 & 0.77 & 0.65 \\
\hline
\end{tabular}

\section{CONCLUSION}

The work discussed here indicates that the displacement of inertia due to WPP integration results in changes in the frequency and damping of oscillation modes. The location of inertia displacement in the system is also of importance. Frequency response controls or WPP output level do not appear to influence these modes (note however that in a highly congested system this might not be the case). The results have been verified using the different techniques outlined in Section III. The analysis technique described in this paper also shows that PMU based analysis can be used to study stability even without complete knowledge of the network. For future situations where traditional Eigenanalysis may be inadequate (large penetration levels of inverter-connected generation, proprietary controllers for grid-connected generation, large penetration of microgrids etc.) this measurement-based method may provide more reliable mode estimates.

In future work, these results will be validated using archived PMU data from real power systems correlated with information about WPP installations and CPP retirements. For example, in [30], it has been observed that modes in the Electric Reliability Council of Texas (ERCOT) network have changed over time, likely due to the addition of large amounts of wind power and the associated transmission build-out. In the future, system planners could use archived PMU data to conduct analyses to evaluate system stability upon WPP installation or CPP retirement. Additionally, PMU data can assist planners in anticipating modes before they become a reality on the system. As the wind penetration level increases, such analyses will become increasingly relevant.

TABLE III

AREA 2 GENERATOR 3 FREQUENCY AND DAMPING ESTIMATES FOR $0.73 \mathrm{~Hz}$ AND 1.22 Hz MODES

\begin{tabular}{|c|c|c|c|c|}
\cline { 2 - 5 } \multicolumn{1}{c|}{} & \multicolumn{2}{c|}{$0.73 \mathrm{~Hz}$ Mode } & \multicolumn{2}{c|}{$1.22 \mathrm{~Hz}$ Mode } \\
\hline Case No. & Freq & Damp & Freq & Damp \\
\hline Base & 0.73 & 0.08 & 1.22 & 4.35 \\
\hline 1 & 0.78 & 0.28 & 1.78 & 3.97 \\
\hline 2 & 0.78 & 0.37 & 1.22 & 4.24 \\
\hline 3 & 0.78 & 0.44 & 1.78 & 4.64 \\
\hline 4 & 0.78 & 0.41 & 1.78 & 4.19 \\
\hline 5 & 0.77 & 0.51 & 1.22 & 4.26 \\
\hline 6 & 0.78 & 0.51 & 1.77 & 4.54 \\
\hline 7 & 0.77 & 0.57 & 1.77 & 4.63 \\
\hline 8 & 0.76 & 0.57 & 1.21 & 4.50 \\
\hline 9 & 0.78 & 0.48 & 1.19 & 5.07 \\
\hline 10 & 0.77 & 0.63 & 1.21 & 4.60 \\
\hline
\end{tabular}

TABLE IV

AREA 2 GENERATOR 4 FREQUENCY AND DAMPING ESTIMATES FOR $0.73 \mathrm{HZ}$ AND $1.22 \mathrm{~Hz}$ MODES

\begin{tabular}{|c|c|c|c|c|}
\cline { 2 - 5 } \multicolumn{1}{c|}{} & \multicolumn{2}{c|}{$0.73 \mathrm{~Hz}$ Mode } & \multicolumn{2}{c|}{$1.22 \mathrm{~Hz}$ Mode } \\
\hline Case No. & Freq & Damp & Freq & Damp \\
\hline Base & 0.73 & 0.06 & 1.22 & 4.36 \\
\hline 1 & 0.78 & 0.12 & 1.79 & 3.89 \\
\hline 2 & 0.78 & 0.32 & 1.22 & 4.35 \\
\hline 3 & 0.78 & 0.50 & 1.78 & 4.42 \\
\hline 4 & 0.78 & 0.35 & 1.79 & 3.99 \\
\hline 5 & 0.77 & 0.51 & 1.22 & 4.52 \\
\hline 6 & 0.78 & 0.50 & 1.78 & 4.43 \\
\hline 7 & 0.77 & 0.59 & 1.78 & 4.45 \\
\hline 8 & 0.76 & 0.57 & 1.21 & 4.79 \\
\hline 9 & 0.78 & 0.52 & 1.22 & 4.72 \\
\hline 10 & 0.77 & 0.63 & 1.21 & 4.87 \\
\hline
\end{tabular}




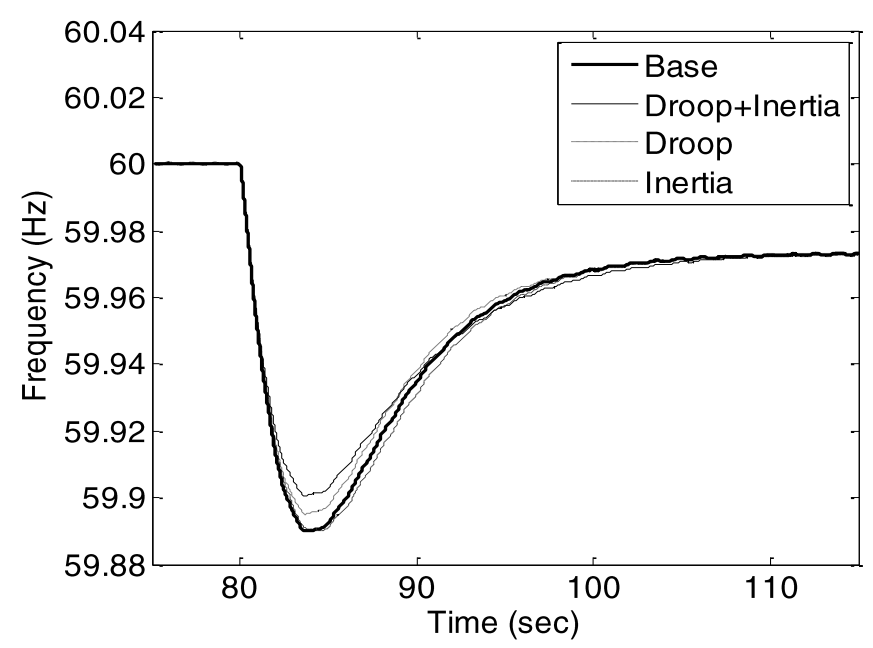

Fig. 10. Frequency response plots with additional WPP controls. TABLE VI

AREA 1 FREQUENCY AND DAMPING ESTIMATES

\begin{tabular}{|c|c|c|c|c|}
\hline \multirow{2}{*}{ Case } & \multicolumn{2}{|c|}{ Generator G1 } & \multicolumn{2}{c|}{ Generator G2 } \\
\hline \multirow{2}{*}{ Base Case } & Freq & Damp & Freq & Damp \\
\cline { 2 - 5 } & - & - & 1.76 & 5.90 \\
\hline \multirow{2}{*}{ Droop } & - & - & 1.76 & 5.71 \\
\cline { 2 - 5 } & 0.78 & 0.52 & 0.77 & 1.14 \\
\hline \multirow{2}{*}{ Inertia } & - & - & 1.76 & 5.74 \\
\cline { 2 - 5 } & 0.77 & 0.68 & 0.76 & 1.04 \\
\hline \multirow{2}{*}{$\begin{array}{c}\text { Droop + } \\
\text { Inertia }\end{array}$} & 1.74 & 5.52 & 1.75 & 5.63 \\
\cline { 2 - 5 } & 0.77 & 0.76 & 0.76 & 1.14 \\
\hline
\end{tabular}

TABLE VII

AREA 2 FREQUENCY AND DAMPING ESTIMATES

\begin{tabular}{|c|c|c|c|c|}
\hline & \multicolumn{2}{|c|}{ Generator G3 } & \multicolumn{2}{c|}{ Generator G4 } \\
\hline Case & Freq & Damp & Freq & Damp \\
\hline \multirow{2}{*}{ Base Case } & 1.21 & 4.27 & 1.21 & 5.05 \\
\cline { 2 - 5 } & 0.78 & 1.24 & 0.77 & 1.29 \\
\hline \multirow{2}{*}{ Droop } & 1.21 & 4.39 & 1.21 & 5.02 \\
\cline { 2 - 5 } & 0.78 & 0.79 & 0.77 & 0.72 \\
\hline \multirow{2}{*}{ Inertia } & 1.20 & 4.13 & 1.21 & 5.02 \\
\cline { 2 - 5 } & 0.78 & 0.93 & 0.78 & 1.04 \\
\hline \multirow{2}{*}{$\begin{array}{c}\text { Droop }+ \\
\text { Inertia }\end{array}$} & 1.20 & 4.29 & 1.21 & 4.93 \\
\cline { 2 - 5 } & 0.77 & 1.18 & 0.77 & 1.31 \\
\hline
\end{tabular}

\section{REFERENCES}

[1] " $20 \%$ Wind Energy by 2030 - Increasing Wind Energy's Contribution to U.S. Electricity Supply." U.S. Department of Energy, May 2008. DOE/GO-102008-2567. Available:

http://www1.eere.energy.gov/windandhydro/pdfs/41869.pdf

[2] Electric Reliability Council of Texas, "ERCOT Grid Operations Wind Integration Report: 05/02/2013", 2013. Available:

http://www.ercot.com/content/gridinfo/generation/windintegration/2013/ 05/ERCOT\%20Wind\%20Integration\%20Report\%2005-02-13.pdf
[3] "Western Wind and Solar Integration Study," National Renewable Energy Laboratory (NREL), Golden, CO., 2010. Available: http://www.osti.gov/energycitations/product.biblio.jsp?osti_id=981991

[4] N. Miller, M. Shao, and S. Venkataraman, "CAISO Frequency Response Study,” GE Energy, 2011. Available: http://www.uwig.org/ReportFrequencyResponseStudy.pdf

[5] J. G. Slootweg and W. L. Kling, "The impact of large scale wind power generation on power system oscillations", Elect. Power Syst. Res., vol. 67, pp. $9-202003$.

[6] G. Tsourakis, B.M. Nomikos and C.D. Vournas, "Contribution of Doubly Fed Wind Generators to Oscillation Damping," IEEE Trans. Energy Conversion, vol.24, no.3, pp.783,791, Sept. 2009.

[7] A. Mendonca and J.A. Peas Lopes, "Impact of large scale wind power integration on small signal stability," Future Power Systems, 2005 International Conference on , Nov. 2005.

[8] D. Gautam, V. Vittal and T. Harbour, "Impact of Increased Penetration of DFIG-Based Wind Turbine Generators on Transient and Small Signal Stability of Power Systems," IEEE Trans. Power Syst., vol.24, no.3, pp.1426,1434, Aug. 2009.

[9] P. Kundur, Power System Stability and Control, McGraw-Hill, New York: 1974, pp. 814.

[10] Manitoba HVDC Research Centre, "PSCAD/EMTDC: Electromagnetic transients program including dc systems," Version 4.2.0.

[11] T.K. Das and G.K. Venayagamoorthy, "Optimal design of power system stabilizers using a small population based PSO," IEEE Power Engineering Society, General Meeting, June 12-16, 2006, Montreal, Quebec.

[12] M. Behnke, A. Ellis, Y. Kazachkov, T. McCoy, E. Muljadi, W. Price, and J. Sanchez-Gasca, "Development and Validation of WECC Variable Speed Wind Turbine Dynamic Models for Grid Integration Studies," in Proc. 2007 WindPower Conference, Los Angeles, USA, June 2007.

[13] M. Singh and S. Santoso, "Dynamic Models for Wind Turbines and Wind Power Plants", National Renewable Energy Laboratory, Golden, CO, Subcontract Report, 2011. Available: http://www.nrel.gov/docs/fy12osti/52780.pdf

[14] J.W. Pierre, D.J. Trudnowski and M.K. Donnelly, "Initial results in electromechanical mode identification from ambient data", IEEE Trans. Power Syst., 1997, 12, (3), pp. 1245-1251.

[15] WECC Renewable Energy Modeling Task Force, "WECC Wind Power Plant Dynamic Modeling Guide", 2010. Available: http://renewne.org/wpcontent/uploads/2012/05/WECCWindPlantDynamicModelingGuide.pdf

[16] E. Muljadi, C.P. Butterfield, A. Ellis, J. Mechenbier, J. Hocheimer, R. Young, N. Miller, R. Delmerico, R. Zavadil, J.C. Smith, "Equivalencing the Collector System of a Large Wind Power Plant." IEEE Power Engineering Society, General Meeting, June 12-16, 2006, Montreal, Quebec.

[17] G. Lalor, A. Mullane and M. O'Malley, "Frequency control and wind turbine technologies", IEEE Trans. Power Syst., vol. 20, no. 4, pp.1905 19132005.

[18] G. Ramtharan , J. B. Ekanayake and N. Jenkins, "Frequency support from doubly fed induction generator wind turbines", Renew. Power Gen., IET, vol. 1, pp.3 -9 2007.

[19] J.F. Conroy and R. Watson, "Frequency Response Capability of Full Converter Wind Turbine Generators in Comparison to Conventional Generation”, IEEE Trans. Power Syst., vol.23, no.2, pp.649,656, May 2008

[20] N.R. Ullah, T. Thiringer and D. Karlsson, "Temporary Primary Frequency Control Support by Variable Speed Wind TurbinesPotential and Applications," IEEE Trans. Power Syst., vol.23, no.2, pp.601,612, May 2008.

[21] A. Buckspan, J. Aho, P. Fleming, Y. Jeong and L. Pao, "Combining droop curve concepts with control systems for wind turbine active power control," Power Electronics and Machines in Wind Applications (PEMWA), 2012 IEEE, July 2012, Denver CO USA.

[22] J. Morren, S.W.H. De Haan, W.L. Kling and J.A. Ferreira, "Wind turbines emulating inertia and supporting primary frequency control," IEEE Trans. Power Syst., vol.21, no.1, pp.433,434, Feb. 2006.

[23] I. Kamwa, A.K. Pradhan and G. Joos, "Adaptive Phasor and FrequencyTracking Schemes for Wide-Area Protection and Control," IEEE Trans. Power Delivery, vol.26, no.2, pp.744,753, April 2011.

[24] T.K. Sarkar and O. Pereira, "Using the matrix pencil method to estimate the parameters of a sum of complex exponentials", IEEE Antennas Propag. Mag., 1995, 37, (1), pp. 48-55. 
[25] M. Bounou, S. Lefebvres and R.P. Malhame, "A spectral algorithm for extracting power system modes from time recordings", IEEE Trans. Power Syst., 1992, 7, (2), pp. 665-672.

[26] P.D. Welch., "The use of fast Fourier transform for the estimation of power spectra: A method based on time averaging over short, modified periodograms," Audio and Electroacoustics, IEEE Transactions on , vol.15, no.2, pp.70,73, Jun 1967.

[27] N. Zhou, D. Trudnowski, J.W. Pierre, S. Sarawgi and N. Bhatt, “An algorithm for removing trends from power-system oscillation data," Power and Energy Society General Meeting - Conversion and Delivery of Electrical Energy in the 21st Century, 2008 IEEE , July 2008, Pittsburgh PA USA.

[28] G. Andersson, R. Atmuri, R. Rosenqvist, and S. Torseng, "Influence of Hydro Units' Generator-to-Turbine Inertia Ratio on Damping of Subsynchronous Oscillations," IEEE Trans. Power Apparatus, vol.PAS103, no.8, pp.2352,2361, Aug. 1984.

[29] M. Klein, G.J. Rogers and P. Kundur, "A fundamental study of interarea oscillations in power systems," IEEE Trans. Power Syst., vol.6, no.3, pp.914,921, Aug 1991.

[30] A. Allen, "Analysis of Transmission System Events and Behavior using Customer-level Voltage Synchrophasor Data," Ph.D. dissertation, Dept. Elec. and Comp. Eng., Univ. of Texas, Austin, TX, 2013. 